\title{
Preface: Progress and Prospects of Research and Practice of Digital Cultural Heritage
}

\author{
Anrong DANG \\ School of Architecture, Tsinghua University, Beijing 100084 \\ Chair of 28th CIPA Symposium (CIPA 2021)
}

Co-hosted by Tsinghua University, ICOMOS China, Tsinghua Heritage Institute for Digitization, and Beijing University of Civil Engineering and Architecture, the CIPA2021 symposium (28th biennial symposium of the international scientific committee for documentation of cultural heritage) was held online successfully at Tsinghua University during August 28th to September 1st, 2021. This is the first time CIPA held a biennial symposium in mainland of China and in online format since its establishment in 1968. The theme of the symposium is "Great Learning \& Digital Emotion". During the 5-day online symposium, opening ceremony \& keynote-speech session-1, education session, outstanding youth forum, 12 sub-theme forums, and keynote-speech session-2 \& closing ceremony were organized, which included 130 more presentations and attracted more than 1,000 online participants from more than 30 countries on five continents to conduct academic exchanges and seminars.

Among all the presentations, four of them are keynote speeches. These include: 1) "deep learning for cultural heritage" by Professor Christian Heipke (President of ISPRS), 2) "space technology in support of world heritage" by Professor Huadong Guo (Academician of Chinese Academy of Sciences), 3) "digital culture heritage and territorial spatial planning - China's practice and perspective" by Professor Jun Chen (Academician of Chinese Academy of Engineering), and 4) "documentation - foundation of any heritage policy" by Professor Teresa Patrício (President of ICOMOS). Besides these keynotes, all other 120 more presentations are selected from the publication papers of ISPRS Annals and Archives.

The progress and prospects of research and practice of digital cultural heritage all over the world can be summarized as theory, technology, and method of CHIM that will be described as follows. Basically, CHIM refers of Cultural Heritage Information Modelling. However, based on CIPA2021 symposium and the paper publications, CHIM is not just Modelling and Model, but the current progress and future prospects of digital cultural heritage research and practice, such as " $\mathrm{C}$ " represents Collection, Collaboration, Coordination, and Conference; " $\mathrm{H}$ " represents High-Speed, High-Quality, High-Tech. and High-Education; "I" represents Integration, Interpret, International, and Intelligent; and " $M$ " represents Multi-Classes, Methodology, Multidisciplinary, and Management. And all of the aspects are included into the following table (see Table 1) and it is clear that CHIM is not only a Model for documentation but also a platform for future intelligent conservation. 
Table 1: CHIM—Progress and Prospects of Digital Cultural Heritage

\begin{tabular}{|c|c|c|c|}
\hline $\begin{array}{l}\text { Key } \\
\text { Letter }\end{array}$ & $\begin{array}{c}\text { Basic } \\
\text { Meaning }\end{array}$ & $\begin{array}{l}\text { Extension } \\
\text { Meaning }\end{array}$ & Description of Progress and Prospects \\
\hline \multirow{5}{*}{$\mathrm{C}$} & Cultural & & Focus on integration of tangible and intangible \\
\hline & & Collection & Collecting cultural related data and information \\
\hline & & Collaboration & International collaboration for conservation \\
\hline & & Coordination & Coordinating in design, development, and action \\
\hline & & Conference & International communication like CIPA symposium \\
\hline \multirow{5}{*}{$\mathrm{H}$} & Heritage & & Architecture, Village, City; Point, Linear, Regional \\
\hline & & High-Speed & Must be act at once because of many kinds of risks \\
\hline & & High-Quality & $\begin{array}{l}\text { High-Precision of cultural heritage data, model, } \\
\text { interpretation, restore, system, and so on }\end{array}$ \\
\hline & & High-Tech. & $\begin{array}{l}\text { Application study on technology, like HBIM, GIS, } \\
\text { RS, GNSS, XR, DL, Eye Tracker, Robot, and so on }\end{array}$ \\
\hline & & High-Education & International training of digital cultural heritage \\
\hline \multirow{5}{*}{ I } & Information & & From data to information to knowledge to intelligent \\
\hline & & Integration & Integration of all kinds of data and technology \\
\hline & & Interpret & Interpret the value system of cultural heritage \\
\hline & & International & $\begin{array}{l}\text { Recognize and conservation the value of cultural } \\
\text { heritage from an international perspective }\end{array}$ \\
\hline & & Intelligent & $\begin{array}{l}\text { Mining the knowledge and intelligent from cultural } \\
\text { heritage by deep learning and artificial intelligence }\end{array}$ \\
\hline \multirow{5}{*}{ M } & Model & & Integration of $2 \mathrm{D} / 3 \mathrm{D} / 4 \mathrm{D}$ model and its attributes \\
\hline & & Multi-Classes & $\begin{array}{l}\text { model cultural heritage requires the integration of } \\
\text { multi-types, multi-scales, and multi-elements }\end{array}$ \\
\hline & & Methodology & Technical approach to model cultural heritage \\
\hline & & Multidisciplinary & $\begin{array}{c}\text { Digital cultural heritage conservation requires } \\
\text { multidisciplinary integration }\end{array}$ \\
\hline & & Management & $\begin{array}{l}\text { Digital cultural heritage conservation requires } \\
\text { intelligent management and governance }\end{array}$ \\
\hline
\end{tabular}


The editors wish to thank all contributing authors and the members of the Editor Committee and Science Committee, namely:

\section{Editor Committee Members:}

Youqiang DONG, Zongfei LI, Wensheng ZHOU, Lie ZHANG, Yinghua MA, Weiyi PEI, Alexandra HARRER, Ying LONG, Li XIE

\section{Science Committee Members (in alphabetical order):}

Abbass Malian (Shahid Rajaee Teacher Training university)

Aiqun Li (Beijing University of Civil Engineering and Architecture)

Alex Yaning Yen (China University of Technology Taipei)

Alexandra Harrer (School of Architecture in Tsinghua University)

Ana Almagro Vidal (Fundacion Montemadrid)

Andrea Adami (Politecnico di Milano)

Andreas Georgopoulos (National Technical University of Athens)

Andrés Mazzini (Facultad de Arquitectura)

Anrong Dang (School of Architecture in Tsinghua University)

Athanasios Moysiadis (University of Thessaly)

Bhavya Ahuja (Development and Research Organization for Nature)

Changfa Zhan (Chinese Academy of Cultural Heritage)

Chen Yang ( College of Architecture and Urban Planning in Tongji University)

Cristiana Achille (Politecnico di Milano)

Dante Abate (The Cyprus Institute)

Efstathios Adamopoulos (University of Turin)

Florian Petrescu (UTCB - Technical University of Civil Engineering Bucharest)

Francesco Fassi (Politecnico di Milano)

Fulong Chen (The Aerospace Information Research Institute)

Fulvio Rinaudo (Politecnico DI Torino - DAD)

Geert Verhoeven (LBI ArchPro)

Grazia Tucci (University of Florence)

Guobin Wang (Beijing University of Technology)

Haiming Yan (ICOMOS China)

Haoying Han (Zhejiang University)

Hongtao Liu (World Heritage Research Center in Southwest Jiaotong University)

Huadong Guo (The Aerospace Information Research Institute)

Hui Lin (Jiangxi Normal University)

Hui Zhai (Kunming University of Science and Technology)

Immo Trinks (Institute for Archaeological Prospection and Virtual Archaeology)

J.F. Jang (Chengchi University) 
Jie He (School of Architecture in Tianjin University)

Jie Zhang (School of Architecture in Tsinghua University)

Jigeng Tang (Southern University of Science and Technology)

Jixiang Shan (The Palace Museum of China)

Jorge Gonzalez (University of South Florida)

José Luis Lerma (Universitat Politècnica de València)

José Manuel Valle Melón (University of the Basque Country)

Jun Chen (National Geomatics Center of China)

Jun Huang (The Shanghai Advanced Research Institute)

Karel Pavelka (Czech Technical Univeristy in Prague)

Kunlong Chen (University of Science \& Technology Beijing)

Li Xie (ICOMOS China)

Lie Zhang (Academy of Arts \& Design in Tsinghua University)

Lihua Rong (Inner Mongolia University of Technolo

Lijun Yu (The Aerospace Information Research Institute)

Mario Santana Quintero (Carleton University)

Miaole Hou (Beijing University of Civil Engineering and Architecture)

Miaoyi Li (School of Architecture and Urban-Rural Planning in Fuzhou University)

Mingxing Hu (School of Architecture in Southeast University)

Minna Silver (University of Oulu)

Mohammad Habib Reza (BRAC University)

Mona Hess (University College London)

Nick W.B. Yang (China University of Technology Taipei)

Normen G.H. Wong (China University of Technology Taipei)

Ona Vileikis (University College London (UCL))

Pankaj Modi (Center for Heritage Initiatives)

Paolo Salonia (National Research Council - ITABC-CNR - Rome)

Peter Dorninger (4D-IT GmbH)

Peter T.Y. Shih (Chiao Tung University)

Pierre Grussenmeyer (INSA Strasbourg)

Pierre Hallot (University of Liège)

Pieter-Jan De Vos (Erfgoed Leiden en Omstreken)

Prafulla Tarachand Janbade (Chandigarh College of Architecture)

Qiming Qin (Institute of GIS and RS in Peiking University)

Qinglin Ma (Shandong University)

Qiong Wu (Academy of Arts \& Design in Tsinghua University)

Rajdeep Routh (Sustain Ably)

Rand Eppich (Universidad Politécnica de Madrid)

Roko Zarnic (FGG University of Ljubljana) 
Sander Münster (Friedrich Schiller University Jena)

Shalini Dasgupta (Heritage Conservation \& Design Centre)

Shixiong Shawn $\mathrm{Hu}$ (East Stroudsburg University of Pennsylvania)

Shuqiang Lv (Beijing University of Civil Engineering and Architecture)

Stratos Stylianidis (Aristotle University of Thessaloniki )

Tim Belden (University of Surrey)

Valentina Bonora (University of Florence)

Victor Ferreira (Lisbon School of Architecture)

Victor Manuel Lopez-Menchero (University of Castilla-La Mancha)

Wei Dong (School of Architecture in Southeast University)

Wei Feng (School of New Media and Communication Tianjin University)

Weiyi Pei (Beijing Re-yuanmingyuan Company Ltd.)

Wensheng Zhou (School of Architecture in Tsinghua University)

Xavier Forde (Heritage New Zealand Pouhere Taonga)

Xianmin Mai (Southwest Minzu University)

Xin Yi (School of Architecture in Southeast University)

Xinyuan Wang (The Aerospace Information Research Institute)

Y.J. Jeng (Quemoy University)

Yael Alef (Israel Antiquities Authority)

Yan He (Beijing Tsinghua Heritage Institute for Digitization)

Yan Zheng (Central Academy of Fine Arts)

Yang Deng (Beijing University of Civil Engineering and Architecture)

Ying Long (School of Architecture in Tsinghua University)

Yingbiao Chen (School of Geography and Remote Sensing in Guangzhou University)

Yinghua Ma (Beijing Tsinghua Heritage Institute for Digitization)

Youqiang Dong (Beijing University of Civil Engineering and Architecture)

Yuan Li (School of Architecture and Civil Engineering in Xiamen University)

Yuhua Wu (Chinese Academy of Cultural Heritage)

Yuliang Yang (Yunnan Normal University)

Yunfei Qiao (Chinese Academy of Cultural Heritage)

Zhifeng Wu (School of Geography and Remote Sensing in Guangzhou University)

Zhou Lv (School of Architecture in Tsinghua University)

Zhuonan Wang (Inner Mongolia University of Technology)

Anrong DANG

Tsinghua Yuan, Beijing, China

September $1^{\text {st }}, 2021$ 